\title{
Identification of Plant Species by Deep Learning and Providing as A Mobile Application
}

\author{
M. Fatih Adak ${ }^{1}$ \\ ${ }^{1}$ Corresponding Author; Sakarya University, Computer Engineering Department; fatihadak@sakarya.edu.tr; \\ $+902642957049$
}

Received 24 July 2020; Revised 28 August 2020; Accepted 4 November 2020; Published online 30 December 2020

\begin{abstract}
Image processing techniques give highly successful results when used deep learning in classification studies. Applications benefit from this kind of work to make life easier. In this study, a mobile application is developed that takes photo of a plant and makes image processing on it to provide information about its name, the time to change the soil, the amount of sun light and nutrition it needs. The model is trained using the Convolutional Neural Networks, and dataset is successfully applied to the network. Currently, the application is capable to classify 43 different plants in mobile environment, and its classification capacity is planned to be expanded with new plant species as a future study. Up to $90 \%$ accuracy is reached in this study with the current version of the application.
\end{abstract}

Keywords: plant classification, deep learning, CNN, mobile system

\section{Derin Öğrenme Kullanılarak Bitki Türlerinin Sınıflandırılması ve Mobil Uygulama Olarak Sunumu}

$\ddot{\mathbf{O z}}$

Görüntü işleme teknikleri kullanılarak yapılan sınıflandırma çalışmalarında yüksek başarılar elde edilmektedir. Hayatı kolaylaştıracak uygulamalar bu tür çalışmalardan faydalanmaktadır. Bu çalışmada geliştirilen mobil uygulama bitkinin resmi çekilerek görüntü analizi yapılıp kullanıcıya bitki hakkında, ismi, toprak değişim süresi, ihtiyaç duyduğu güneş ve destek besin miktarı gibi faydalı bilgiler sunulmaktadır. Geliştirilen model Convolutional Neural Network ile eğitilmiş olup bu çalışmada derin öğrenme başarılı bir şekilde kullanılmıştır. Mobil ortamda 43 farklı bitki türünü tanıyabilen uygulama yeni bitki türlerinin eklenmesi ile kapsamının genişletilmesi planlanmıştır. Çalışma şu an gelinen konum itibarıyla \%90'lara varan doğruluk değeri elde edilebilmektedir.

Anahtar Kelimeler: bitki sınıflandırma, derin öğrenme, CNN, mobil sistemler

\section{Introduction}

Today, deep learning is begun to be used in every field as it became highly popular with increasing number of deep learning libraries. Agricultural sector is one of the many fields where important developments and research studies are being carried out. In this study, a mobile application is developed that classifies 43 different plant species and provides the user with information about the classified plant such as the environment temperature, amount of water, time to change the soil, amount of sun light and nutrition amount it needs. This would enable the user to reach identifying and useful information about a plant in his/her home or any other plant he/she sees outside and wonder or wants to buy. Deep learning techniques are used in this study and high accuracy rates are reached. The study is especially useful as it makes life easier. In addition, since a rapid transition to autonomous systems is present in agricultural sector, this type of studies also shed light on new research in the field. There are several similar studies in agricultural sector. For example, Dyrmann et al. classified 22 different plant species using deep 
learning techniques in their study and reached a $86.2 \%$ success rate [1]. In a similar study, a classification was carried out based on leaf vein patterns where $93.33 \%$ success was reached in 3 different datasets used [2]. In another study using leaf vein patterns, 95\% level of success was reached [3]. Again in a study based on leaf vein patterns, different classification methods were compared and neural networks were shown to perform best, followed by support vector machines (SVM) [4]. SVM can be seen in similar studies, 32 species classified and the average accuracy obtained in testing data is 82.67\% [5]. In another study a hybrid model is used by SVM the proposed model yields to improve the identification rate up to $98.9 \%$ and $93.3 \%$ for both Flavia and Swedish dataset respectively [6]. Automatic plant detection proposed by using SVM again and they reached $91.25 \%$ accuracy [7]. As can be seen, image processing techniques have been actively used in identification of different plant species. Convolutional Neural Networks (CNN) are known to produce favorable results in processing image data in deep learning. In a study using this method between $73.05 \%-93.41 \%$ success rate was reached [8]. Using CNN as a feature selection technique was shown to classify flowers in 5 basic classes with up to 96-98\% level of accuracy [9]. Feature selection was also carried out by other studies. There are certain methods used for feature selection each having its own advantages and disadvantages. Among these methods, CNN was shown to reach high accuracy rates [10]. The low performance of other methods in feature selection lead to a search for alternative methods besides CNN. Ren et al., for example, used density based image clustering instead of the traditional methods for clustering and reached high accuracy rates [11]. One of the problems in applying autonomous systems is that the camera angle should be perfectly proper while taking photo of a plant. The deficiency caused by an inefficient photo might be corrected up to a certain level. However, the accuracy rate of the classification would decrease. Some research dealt with this aspect of the subject, and managed to identify a wild plant, for example, present in a crowded image. Again CNN networks were used in that study [12]. Additionally, there have been successful studies to diagnose diseases in plants using CNN and image processing techniques [13][18]. From the researches, it can be observed that CNN reaches high success rates. In this study, CNN is used to classify 43 different plants. This study can be used as a supplementary tool to various agricultural applications [19] or can be used as a separate module as well.

This study is organized as follows. Formation of the dataset and feature selection are explained in Section II. The method used and the structure of the network are given in Section III. Section IV provides the findings for different scenarios. Finally, general conclusions are given in the last section.

\section{Materials}

\subsection{Creating The Dataset}

The dataset of the study is constructed by gathering several images of 43 different plants taken from various directions. The plants are chosen among common plants that one can come across in daily life. This way it is aimed to increase the usage of the application in social life. The dataset includes approximately 100 different images for each of the 43 plants. This makes a total of 4559 images. Names of the plants are given in Table I. Following information is collected for each plant species and included in the dataset: name, required temperature, required irrigation amount, preferred soil type, sun light requirement, time to change soil, supplementary nutrition.

Every image is scaled into the size of $224 \times 224$ and the RGB (red, green, blue) pixel values of the images are stored in the dataset. Thus, input shape is formed as $(224,224,3) .80 \%$ of the dataset is used for training and the remaining $20 \%$ is used for testing and validation. The formation of training dataset was chosen by random for each of plant species. Most of the images were created using ready-made pictures. Some manual shots were made. Many of these handheld shots were created in a bright environment and some were shot in room light. 
Table 1 Species used in dataset

\begin{tabular}{|l|l|l|l|}
\hline Plant ID & \multicolumn{1}{|c|}{ Name } & Plant ID & \multicolumn{1}{c|}{ Name } \\
\hline 1 & African Violet & 2 & Aloe Vera \\
\hline 3 & Anthurium Flower & 4 & Monstera Deliciosa \\
\hline 5 & Cactus & 6 & Kentia Palm \\
\hline 7 & Asparagus & 8 & Crassula Ovata \\
\hline 9 & Sansevieria & 10 & Spathipyllum wallisii \\
\hline 11 & Aphelandra & 12 & Aglaonema \\
\hline 13 & Areca Palm & 14 & Euphorbia Pulcherrima \\
\hline 15 & Dieffenbachia & 16 & Christmas Cactus \\
\hline 17 & Gloxinia & 18 & Guzmania Ostara \\
\hline 19 & Yucca Flower & 20 & Maranta Leucorneura \\
\hline 21 & Nephrolepis Exaltata & 22 & Campsis Radicans \\
\hline 23 & Jasminum Sambac & 24 & Bougainvillea \\
\hline 25 & Kumquat Tree & 26 & Norfolk Island Pine \\
\hline 27 & Broom & 28 & Savin Juniper \\
\hline 29 & Tradescantia Flower & 30 & Rhododendron \\
\hline 31 & Geranium & 32 & Orchids \\
\hline 33 & Schefflera & 34 & Chrysanthemum \\
\hline 35 & Rabbits’ ears & 36 & Begonia \\
\hline 37 & Petunia Flower & 38 & Jonquil \\
\hline 39 & Croton Plant & 40 & Lily \\
\hline 41 & Rose Laurel & 42 & Hyacinth \\
\hline 43 & Anemone Flower & & \\
\hline
\end{tabular}

\section{Method}

The model to be used for plant identification and information supply in mobile environment is developed using deep learning and CNN networks. CNN networks are special networks that are used particularly in processing image data. CNN was first introduced by LeCun et al. in 1990 [20]. Image classification is carried out by using determining factors. These might be for example leaf side patterns in plants. One of the important strengths of a CNN structure is its filters. Thus, image classification can be successfully carried out independent of its location. This would avoid astronomical number of weights. There are various layers in CNN networks. Among them, convolution layer has an important role.

Four important parameters are used in CNN. These are: filter size, zero padding amount, stride and number of filters. Output volume of layer is calculated as WxHxD. W, H and D are calculated as in Eq. (1), where $\mathrm{F}$ is the filter size, $\mathrm{P}$ is the zero-padding amount, $\mathrm{S}$ is stride, and $\mathrm{K}$ is the number of filters.

$$
\begin{aligned}
& W=\left(W_{i n p}-F+2 P\right) / S+1 \\
& H=\left(H_{i n p}-F+2 P\right) / S+1 \\
& D=K
\end{aligned}
$$

Total number of parameters is 3,613,803 in the model, and 1,355,819 of them are trainable parameters. The values used for the parameters are given in Table II.

Table 2 Parameters used in the model

\begin{tabular}{|l|l|}
\hline Shear range & 0.2 \\
\hline Zoom range & 0.2 \\
\hline Rotation range & 40 \\
\hline Width shift range & 0.2 \\
\hline Height shift range & 0.2 \\
\hline Fill mode & Nearest \\
\hline Batch size & 32 \\
\hline Optimizer & Adam \\
\hline
\end{tabular}


Padding is applied for the images from different angles and they are supplied as input to the network after convolutional transform. The images are processed in different layers and its class is determined in softmax layer at the end. Zero padding is applied to every convolution layer. Data that is supplied in the form of $(224 \times 224 \times 3)$ is passed through weights of $112 \times 112 \times 32$ dimensions by convolutional transform, since the batch size is 32 . This is followed by $56 \times 56,28 \times 28,14 \times 14,7 \times 7$ dimensions. Fig. 1 gives the representation of the mobile application. When the application is opened, an image of the plant is taken by the use of camera. Then, by pressing the "Find species" button, the image data is supplied to the trained CNN to make a prediction. Then, the screen displays the output of the predicted species and useful information about it.
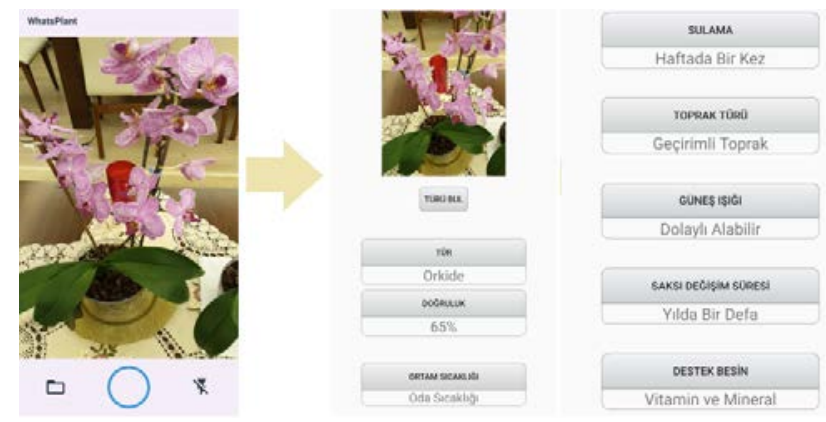

Figure 1 Working procedure of the application

The model used in this study is summarized in Fig. 2. Images taken with camera are used also in training, testing and application phases to enable higher accuracy of the model.

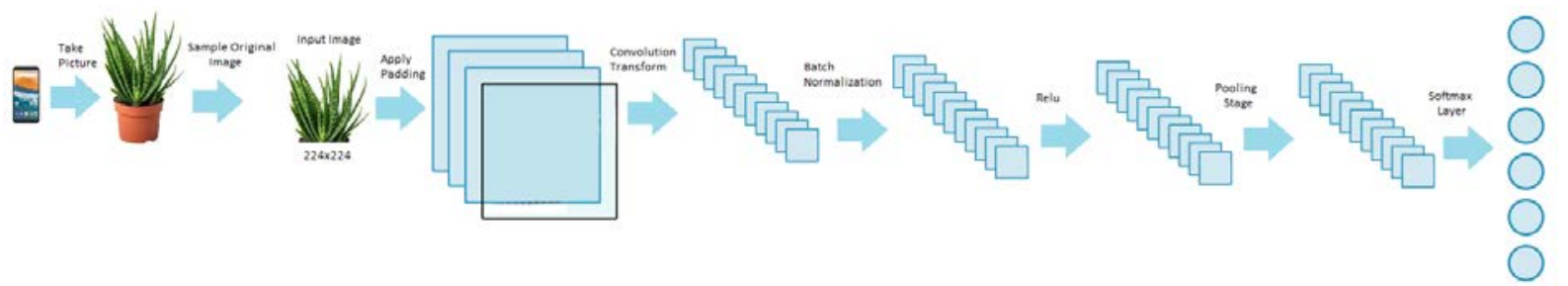

Figure 2 Overview of the proposed model

\section{Results}

Six different scenarios were used to train the model. The scenarios and their results are given in Table III. The model was run with 10, 15, 20, 25, 30 and 40 number of epochs, and no new scenarios were tested if the curves indicated a negative trend. The scenario with 30 epochs performed best in terms of both accuracy and loss values. Accuracy rates go beyond $90 \%$ in training phase. However, in that case, the rate of accuracy in testing begins to decrease. Test phase is taken into account for the accuracy rate, since it can serve as a performance criterion. Training and test accuracy rates for the six scenarios are given in Fig. 3. Scenario (d) that has 30 epochs has the best curve. In all scenarios, the accuracy level of the test was higher than the training phase at the beginning. This indeed shows that this dataset can be trained using low number of epochs.

ROC (Receiver operating characteristic) analysis of the test data is performed for the 6 scenarios and the results are given in Table IV. Again, the scenario with 30 epochs has the best values. The reason for the low values is due to the ROC analysis being a method preferred rather in binary classification. Thus, the values are expected to decrease when used in multiple classification. Table IV also gives what would the values be if it was a binary classification. 


\section{Fatih Adak}

Table 3 Results for different scenarios

\begin{tabular}{|c|c|c|c|c|}
\hline Epoch & Accuracy & $\begin{array}{c}\text { Val } \\
\text { Accuracy }\end{array}$ & Loss & $\begin{array}{c}\text { Val } \\
\text { Loss }\end{array}$ \\
\hline 10 & 0.7893 & 0.7586 & 0.6487 & 0.7566 \\
\hline 15 & 0.8318 & 0.7744 & 0.4982 & 0.5260 \\
\hline 20 & 0.8504 & 0.7533 & 0.4436 & 0.5422 \\
\hline 25 & 0.8750 & 0.7638 & 0.3739 & 0.4193 \\
\hline 30 & $\mathbf{0 . 8 7 5 7}$ & $\mathbf{0 . 7 8 9 3}$ & $\mathbf{0 . 3 5 6 2}$ & $\mathbf{0 . 3 7 6 7}$ \\
\hline 40 & 0.9053 & 0.7779 & 0.2833 & 0.3506 \\
\hline
\end{tabular}

Accuracy value is the ratio of correct predictions to all predictions. Precision is the ratio of true positives to all positives. Thus, a higher precision value means a higher true positive detection capability of the model. Recall value is the ratio of true positives to all actual positives. F1 score is the weighted average of precision and recall values. Thus, in ROC analysis, F1-score is more important than the accuracy value. This again reveals that the best scenario is the fifth one.

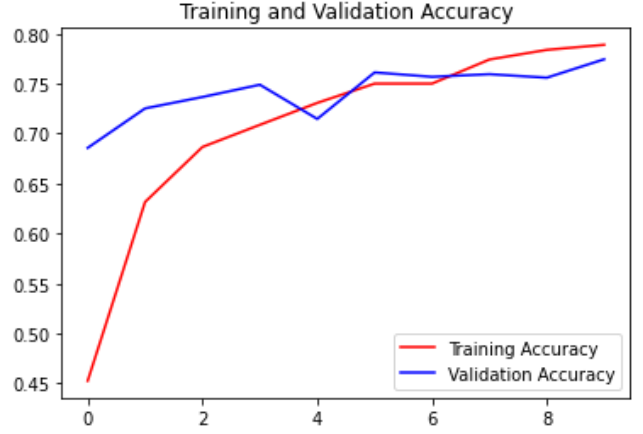

(a)

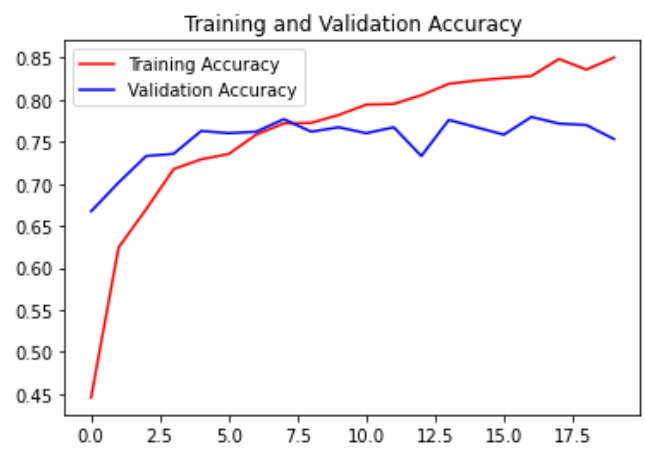

(c)

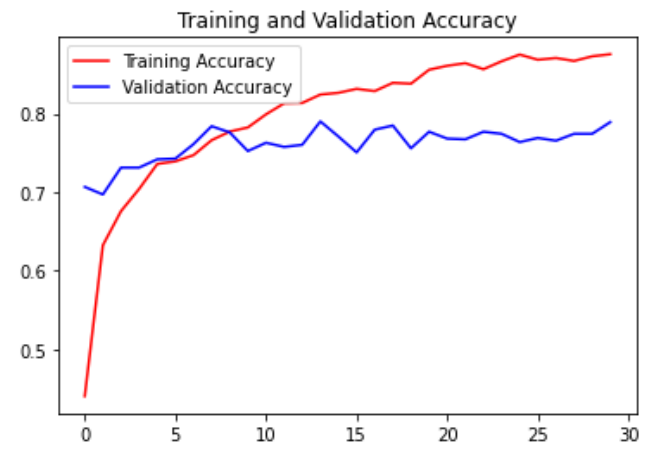

(e)

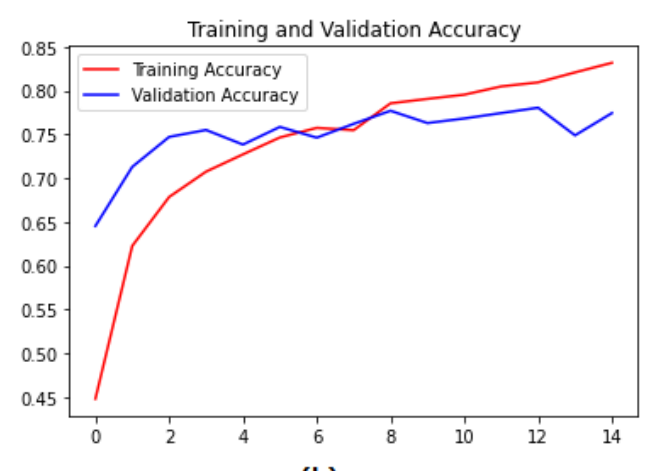

(b)

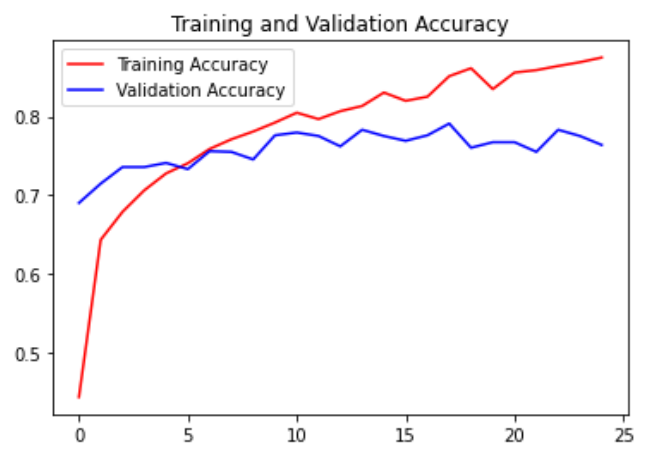

(d)

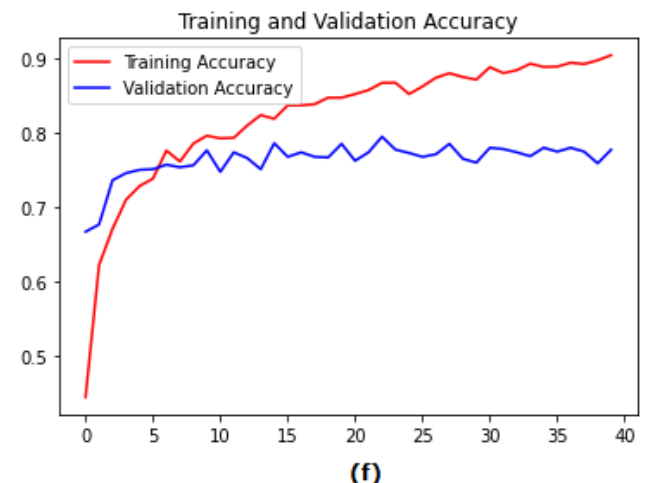

Figure 3 Accuracy values of the scenarios, (a) 10 epoch, (b) 15 epoch, (c) 20 epoch, (d) 25 epoch, (e) 30 epoch, (f) 40 epoch 
Table 4 ROC analysis results of different scenerios

\begin{tabular}{|c|c|c|c|c|}
\hline Epoch & Accuracy & $\begin{array}{c}\text { Val } \\
\text { Accuracy }\end{array}$ & Loss & $\begin{array}{c}\text { Val } \\
\text { Loss }\end{array}$ \\
\hline 10 & 0.7893 & 0.7586 & 0.6487 & 0.7566 \\
\hline 15 & 0.8318 & 0.7744 & 0.4982 & 0.5260 \\
\hline 20 & 0.8504 & 0.7533 & 0.4436 & 0.5422 \\
\hline 25 & 0.8750 & 0.7638 & 0.3739 & 0.4193 \\
\hline 30 & $\mathbf{0 . 8 7 5 7}$ & $\mathbf{0 . 7 8 9 3}$ & $\mathbf{0 . 3 5 6 2}$ & $\mathbf{0 . 3 7 6 7}$ \\
\hline 40 & 0.9053 & 0.7779 & 0.2833 & 0.3506 \\
\hline
\end{tabular}

\section{Conclusions}

Smart systems that make life easier are increasingly becoming widespread in every field. Deep learning techniques play an important role in designing these smart systems. In this study, a mobile application is developed that takes photo of a plant and uses CNN to provide information about its name, and its soil, water, temperature, sun light and nutrition requirements. A quick way of learning a plant's requirements would provide convenience in social life. The information is supplied to the user through the mobile application. The model and the tests reached high accuracy rates. The favorable results showed that CNN can be successfully used in image processing of this type or of other similar types. Every new pattern can be supplied to the network as a training input to increase the accuracy rate of the model. This can be easily achieved with CNN. As a future study, the model can be made more detailed by adding other plant species or updating it to classify even sub-species under certain species. Inspiring from this type of studies, useful models can be developed in smart agricultural applications.

\section{References}

[1] M. Dyrmann, H. Karstoft, and H. S. Midtiby, "Plant species classification using deep convolutional neural network,” Biosyst. Eng., vol. 151, pp. 72-80, Nov. 2016, doi: 10.1016/j.biosystemseng.2016.08.024.

[2] P. Barré, B. C. Stöver, K. F. Müller, and V. Steinhage, "LeafNet: A computer vision system for automatic plant species identification,” Ecol. Inform., vol. 40, pp. 50-56, Jul. 2017, doi: 10.1016/j.ecoinf.2017.05.005.

[3] G. L. Grinblat, L. C. Uzal, M. G. Larese, and P. M. Granitto, "Deep learning for plant identification using vein morphological patterns,” Comput. Electron. Agric., vol. 127, pp. 418424, Sep. 2016, doi: 10.1016/j.compag.2016.07.003.

[4] J. W. Tan, S.-W. Chang, S. Binti Abdul Kareem, H. J. Yap, and K.-T. Yong, "Deep Learning for Plant Species Classification using Leaf Vein Morphometric,” IEEE/ACM Trans. Comput. Biol. Bioinforma., pp. 1-1, 2018, doi: 10.1109/TCBB.2018.2848653.

[5] A. Ambarwari, Q. J. Adrian, Y. Herdiyeni, and I. Hermadi, "Plant species identification based on leaf venation features using SVM," TELKOMNIKA (Telecommunication Comput. Electron. Control., vol. 18, no. 2, p. 726, Apr. 2020, doi: 10.12928/telkomnika.v18i2.14062.

[6] H. F. Eid and A. Abraham, "Plant species identification using leaf biometrics and swarm optimization: A hybrid PSO, GWO, SVM model,” Int. J. Hybrid Intell. Syst., vol. 14, no. 3, pp. 155-165, Mar. 2018, doi: 10.3233/HIS-180248. 
[7] M. A. Islama, S. I. Yousuf, and M. M. Billah, “Automatic Plant Detection Using HOG and LBP Features With SVM,” Int. J. Comput., vol. 33, no. 1, pp. 26-38, 2019.

[8] I. Gogul and V. S. Kumar, "Flower species recognition system using convolution neural networks and transfer learning," in 2017 Fourth International Conference on Signal Processing, Communication and Networking (ICSCN), 2017, pp. 1-6, doi: 10.1109/ICSCN.2017.8085675.

[9] M. Toğaçar, B. Ergen, and Z. Cömert, "Classification of flower species by using features extracted from the intersection of feature selection methods in convolutional neural network models," Measurement, vol. 158, p. 107703, Jul. 2020, doi:

10.1016/j.measurement.2020.107703.

[10] M. Momeny, A. Jahanbakhshi, K. Jafarnezhad, and Y.-D. Zhang, “Accurate classification of cherry fruit using deep CNN based on hybrid pooling approach," Postharvest Biol. Technol., vol. 166, p. 111204, Aug. 2020, doi: 10.1016/j.postharvbio.2020.111204.

[11] Y. Ren, N. Wang, M. Li, and Z. Xu, “Deep density-based image clustering,” Knowledge-Based Syst., vol. 197, p. 105841, Jun. 2020, doi: 10.1016/j.knosys.2020.105841.

[12] W. Qian et al., "UAV and a deep convolutional neural network for monitoring invasive alien plants in the wild," Comput. Electron. Agric., vol. 174, p. 105519, Jul. 2020, doi: 10.1016/j.compag.2020.105519.

[13] K. P. Ferentinos, "Deep learning models for plant disease detection and diagnosis,” Comput. Electron. Agric., vol. 145, pp. 311-318, Feb. 2018, doi: 10.1016/j.compag.2018.01.009.

[14] Y. Osako, H. Yamane, S.-Y. Lin, P.-A. Chen, and R. Tao, "Cultivar discrimination of litchi fruit images using deep learning,” Sci. Hortic. (Amsterdam)., vol. 269, p. 109360, Jul. 2020, doi: 10.1016/j.scienta.2020.109360.

[15] J. Chen, J. Chen, D. Zhang, Y. Sun, and Y. A. Nanehkaran, "Using deep transfer learning for image-based plant disease identification,” Comput. Electron. Agric., vol. 173, p. 105393, Jun. 2020, doi: 10.1016/j.compag.2020.105393.

[16] S. Fan et al., "On line detection of defective apples using computer vision system combined with deep learning methods,” J. Food Eng., vol. 286, p. 110102, Dec. 2020, doi: 10.1016/j.jfoodeng.2020.110102.

[17] C. W. Yohannese and T. Li, “A Combined-Learning Based Framework for Improved Software Fault Prediction,” Int. J. Comput. Intell. Syst., vol. 10, no. 1, p. 647, 2017, doi: 10.2991/ijcis.2017.10.1.43.

[18] A. Krishnaswamy Rangarajan and R. Purushothaman, "Disease Classification in Eggplant Using Pre-trained VGG16 and MSVM,” Sci. Rep., vol. 10, no. 1, p. 2322, Dec. 2020, doi: 10.1038/s41598-020-59108-x. 
[19] M. F. Adak, "Modeling of Irrigation Process Using Fuzzy Logic for Combating Drought," Acad. Perspect. Procedia, vol. 2, no. 2, pp. 229-233, Oct. 2019, doi:

10.33793/acperpro.02.02.34.

[20] Y. LeCun, K. Kavukcuoglu, and C. Farabet, "Convolutional networks and applications in vision," in Proceedings of 2010 IEEE International Symposium on Circuits and Systems, 2010, pp. 253-256, doi: 10.1109/ISCAS.2010.5537907. 